\title{
Laparoscopic Live Donor Nephrectomy: Experience of High-Volume Center with 2,477 Cases
}

\author{
Sefa Alperen Ozturk ${ }^{a}$ Yucel Yuksel $^{b}$ Halil Erbis $^{b}$ Ibrahim Aliosmanoglu $^{b}$ \\ Mehmet Sarier $^{c}$ Ozlem Yayar $^{d}$ Havva Asuman Yavuz ${ }^{d}$ Alper Demirbas ${ }^{b}$

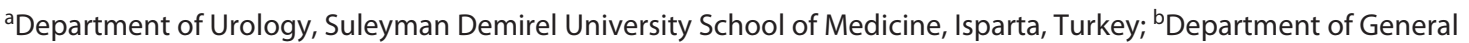

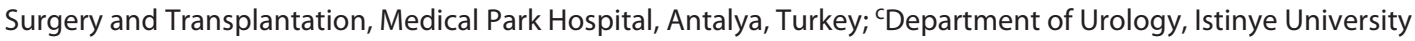 \\ Medical Faculty, Istanbul, Turkey; ${ }^{\text {Department }}$ of Nephrology and Transplantation, Medical Park Hospital, Antalya, \\ Turkey
}

\section{Keywords}

Laparoscopic live donor nephrectomy - Tips and tricks . Obesity - Warm ischemia time - Operation time - Multiple renal arteries

\section{Abstract \\ Objective: Donors' health and safety are mandatory in the living-donor kidney transplantation procedure. Laparoscop- ic live donor nephrectomy (LLDN) provides an increase in donor numbers with its benefits and becomes a standard of care. We aimed to explain the results, complication rates, tips, and tricks of the largest number of LLDN case series ever performed in the literature. Materials and Methods: Be- tween August 2012 and December 2019, 2,477 live donor case files were analyzed retrospectively. Age, gender, hospi- talization times, body mass index, warm ischemia times, op- eration times, numbers of arteries, side of the kidneys, and complications were noted. Results: 1,421 (57.4\%) of 2,477 donors were female $(p=0.007)$. Operation times and warm ischemia times were found longer in right-sided LLDN and donors with multiple renal arteries $(p=0.046,<0.001$, and $<0.001$, respectively). Obesity $\left(\mathrm{BMl}>30 \mathrm{~kg} / \mathrm{m}^{2}\right)$ did not affect}

karger@karger.com

(c) 2020 S. Karger AG, Basel

www.karger.com/uin

Karger" warm ischemia times while prolonging the operation times $(p=0.013)$. Hospitalization times and numbers of complications were higher in obese donors. Conclusions: LLDN seems to be a reliable solution with fewer complications and higher satisfaction rates. We hope to illuminate the way with tips and trick points for beginner transplant surgeons based on the experience obtained from 2,477 LLDN cases.

(c) 2020 S. Karger AG, Basel

\section{Introduction}

Nowadays, kidney transplantation is the optimal treatment for end-stage renal disease (ESRD) patients [1]. The dead-end for the transplantation is lower numbers of the graft kidneys. After live donor nephrectomy starts being performed by surgeons, the pool of the graft has enlarged. There are several surgical procedures for harvesting the kidneys from live donors. At present, laparoscopic live donor nephrectomy (LLDN) is a standard surgical method that was defined by Ratner et al. in 1995 [2].

LLDN encourages people to kidney donation [3]. Many transplantation centers use LLDN as a standard 

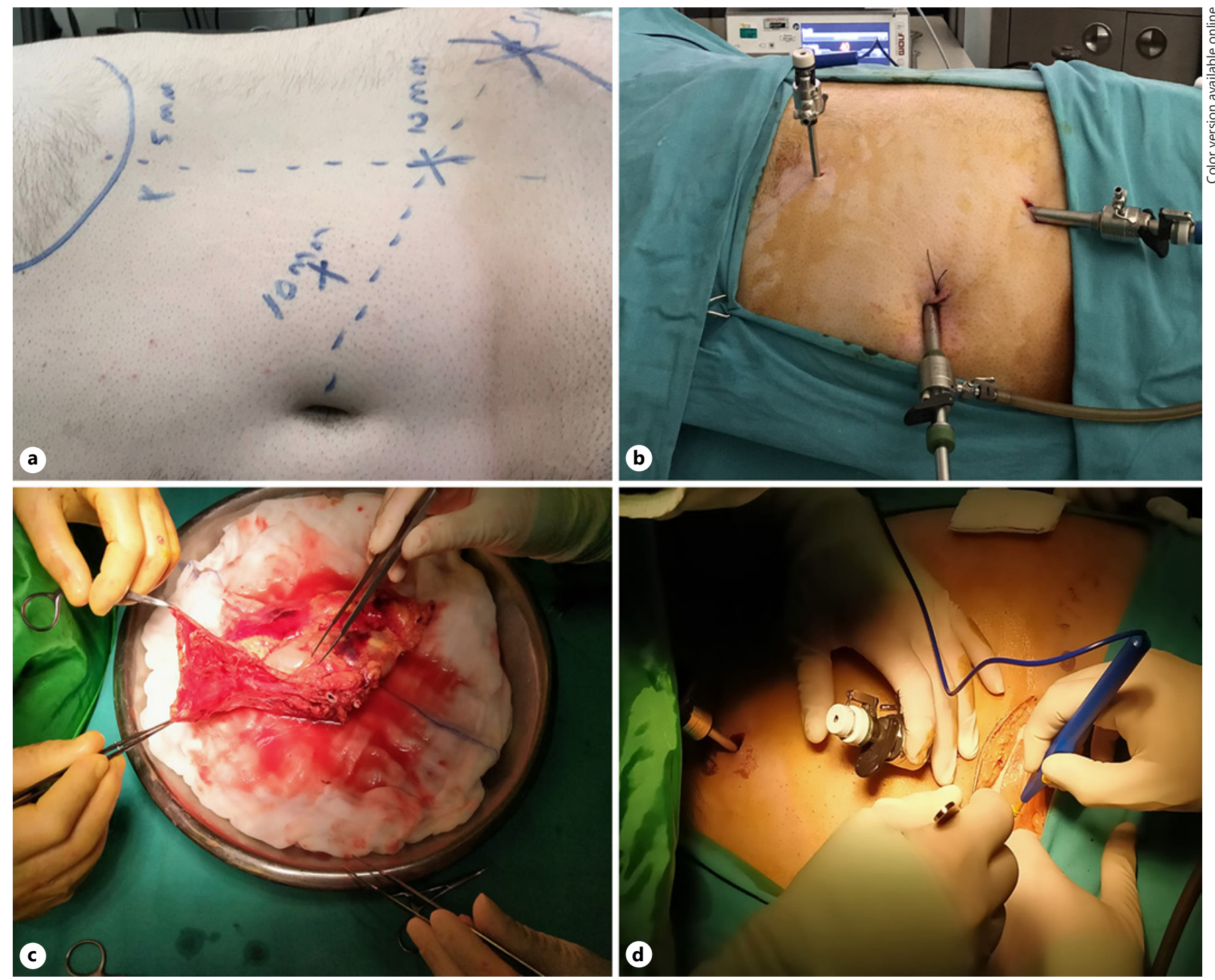

Fig. 1. Surgical tips: anatomic landmarks for trocar entries (a), location of trocars (b), ureter and gonadal vein (c), and Pfannenstiel incision (d).

technique. Reduced recovery times, less postoperative pain, better cosmetic results, and lower costs are the main benefits of laparoscopy. No significant differences were found between LLDN and open donor nephrectomy (ODN) about graft functions [4-6].

Beyond all advancements, there are still risks and complications, especially bleeding, thromboembolism, vascular/ureteral injuries, prolonged surgery and ischemia times, postoperative chylous leakages, and lymphocele [7, 8]. In this study, we aimed to elucidate the results, complications rates, tips, and trick points of LLDN in our practice.

\section{Materials and Methods}

\section{Data Collection}

The study period was defined between August 2012 and December 2019. The results of 2,477 LLDN that were performed in Antalya Medical Park Hospital Organ Transplantation center were analyzed retrospectively. After obtaining the local ethics committee approval (No. 2020/7), live donors' medical, surgical, and psychosocial conditions were extensively evaluated. The laterality of the donor's kidneys was determined scintigraphically according to their separated kidney functions and the number of arteries detected by computerized tomography.

Live donor case files were analyzed and their age, gender, hospitalization times (HT), body mass index (BMI), warm ischemia times (WIT), operation times (OT), numbers of arteries, side of the 
Table 1. Overall statistics of donors

\begin{tabular}{lrr}
\hline & Mean & Standard deviation \\
\hline Age, years & 47.23 & 13.37 \\
OT, min & 77.15 & 16.78 \\
WIT, s & 210.8 & 54.6 \\
BMI, kg/m & 27.73 & 5.15 \\
HT, day & 3.2 & 0.6 \\
\hline
\end{tabular}

OT, operation time; WIT, warm ischemia time; HT, hospitalization time; BMI, body mass index.

kidneys, conversion to open surgery, and other postoperative complications were noted. Eight LLDN were completed with ODN because of vascular injury during hiler dissection.

All data were evaluated by IBM SPSS Statistics version 22 (IBM SPSS, Turkey). The Mann-Whitney U test or Kruskal-Wallis test was used for numerical variables. For analyzing the categorical data, the $\chi^{2}$ test or Fisher test was used. $p$ value $<0.05$ was considered statistically significant.

\section{Surgical Method}

All LLDN were performed transperitoneally by 3 surgeons. After the patient was placed in a lateral decubitus position, the operation table was flexed. Generally, 3 trocars were used. For $30^{\circ}$ optic entry, the $10-\mathrm{mm}$ trocar was placed lateral to the rectus muscle over umbilicus, with a modified Hasson technique [9], the 5-mm trocar was placed under the arcus costalis (midaxillary line), and the other $10-\mathrm{mm}$ trocar was placed one-third of the distance laterally on a line drawn from the umbilicus to the left/ right anterior superior iliac spine (SIAS) (shown in Fig. 1a, b). The insufflation pressure was $14 \mathrm{~mm} \mathrm{Hg}$. After mobilizing and mediating the colon, Gerota's fascia was opened. The gonadal vein and ureter were dissected and then clipped and extracted together for not deteriorating the ureter's blood supply (shown in Fig. 1c). After identifying the renal vein and renal artery, adrenal and lumbar veins were clipped and then cut by scissors. During the cutting of the adrenal vein, 20-mg furosemide was injected intravenously by anesthesiologists. Low transverse suprapubic (Pfannenstiel) incision was made for extracting the kidney (shown in Fig. 1d). Each renal vein and the renal artery were clipped with 3 large or extra-large Hem-o-lok clips. (After using the clips on 1,860 patients, we switched to vascular staplers.) The kidney was manually extracted through the incision with Gerota's fascia. On the back table, the kidney was flushed with papaverine and HTK solution fluid and then stored on ice slush.

\section{Results}

Overall statistics of 2,477 LLDN are shown in Table 1. The number of female donors was higher than males $(1,421$ vs. 1,$056 ; p=0.007)$. However, female donors' WIT
Table 2. Comparison of data of the patients by gender

\begin{tabular}{lccc}
\hline & Gender & \multirow{2}{*}{$p$ value } \\
\cline { 2 - 3 } & female & male & \\
\hline Age, years & $47(18-87)^{*}$ & $48(18-85)^{*}$ & 0.75 \\
N (\%) & $1,421(57.4)$ & $1,056(42.6)$ & 0.007 \\
BMI, kg/m & & & \\
$\quad<30$ & $932(65.6 \%)^{\mathrm{a}}$ & $818(77.5 \%)^{\mathrm{a}}$ & $<0.001$ \\
$>30$ & $489(34.4 \%)^{\mathrm{a}}$ & $238(22.5 \%)^{\mathrm{a}}$ & \\
HT, day & $3(2-9)^{*}$ & $3(2-7)^{*}$ & 0.8 \\
WIT, s & $191(113-492)^{*}$ & $192(120-492)^{*}$ & 0.008 \\
OT, min & $72(40-210)^{*}$ & $75(50-210)^{*}$ & 0.001 \\
Graft side & & & 0.19 \\
$\quad$ Left & $1,380(57.1 \%)$ & $1,035(42.9 \%)$ & \\
$\quad$ Right & $41(66.1 \%)$ & $21(33.9 \%)$ & 0.06 \\
Arteries, $n$ & & & \\
1 & $1,133(79.7 \%)$ & $801(75.9 \%)$ & \\
2 & $250(17.6 \%)$ & $216(20.5 \%)$ & \\
3 & $36(2.5 \%)$ & $34(3.2 \%)$ & \\
4 & $2(0.1 \%)$ & $5(0.5 \%)$ & \\
\hline
\end{tabular}

WIT, warm ischemia time; OT, operation time; HT, hospitalization time; BMI, body mass index. ${ }^{*}$ Median (min-max) values. ${ }^{a}$ The values with the same letters are not statistically different $(p<0.001)$.

and OT were shorter ( $p=0.008$ and 0.001 , respectively). HT is not affected by gender (shown in Table 2).

2,415 of 2,477 LLDN were left sided (ILLDN). When comparing WIT by sides, right-sided LLDN (rLLDN) had longer times $(p<0.001)$. The median OT results seemed similar ( $72 \pm 40-210$ vs. $78.5 \pm 50-210)$. As expected, the existence of multiple arteries extended the OT and WIT (shown in Table 3). We noticed that obesity was related to longer $\mathrm{OT}, \mathrm{HT}$, and postoperative complications (shown in Table 4). Operation times changing by years are shown in Figure 2.

\section{Discussion}

Living donor nephrectomy is against the first rule of the medicine, "primum non nocere" [10]. A healthy human's healthy organ is extracted from him and transplanted to another person. In the beginning, kidneys were harvested from only cadavers and that is why ESRD patients have to wait long years for the right kidney. Through the development of technology and surgical techniques, LLDN has been begun to be performed, and it enlarges the pool of kidney donation. 
Fig. 2. Operation time change by years. OT, operation time.

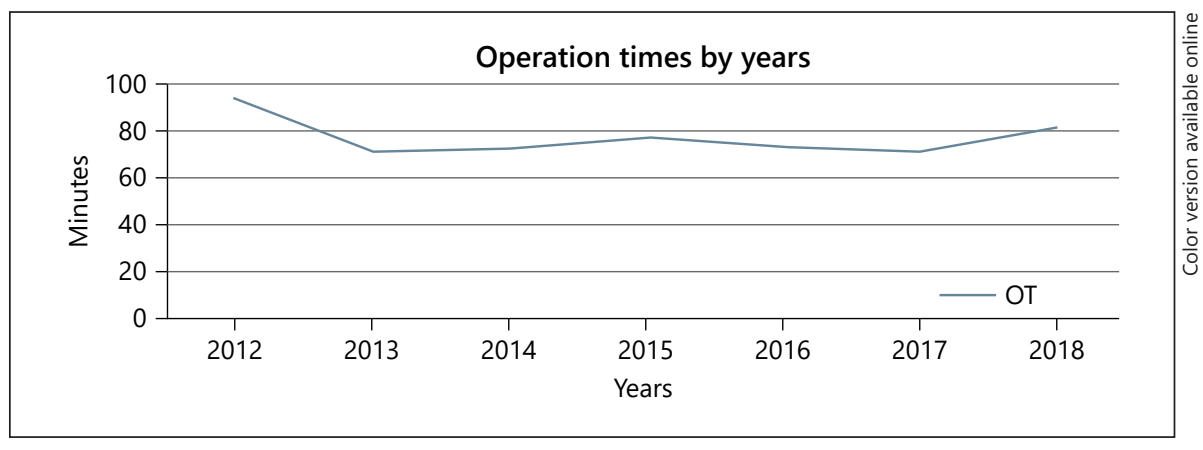

Table 3. Effects of BMI, graft side, and artery number on OT and WIT

\begin{tabular}{lrrrr}
\hline & OT, min & $p$ value & WIT, s & $p$ value \\
\hline $\begin{array}{l}\text { BMI, kg/m² } \\
\quad 30\end{array}$ & $72(40-210)$ & 0.013 & $191(113-492)$ & 0.143 \\
$\quad>30$ & $74(40-210)$ & & $192(120-492)$ & \\
$\begin{array}{l}\text { Graft side } \\
\quad \text { Left }\end{array}$ & $72(40-210)$ & 0.046 & $192(113-492)$ & $<0.001$ \\
$\quad$ Right & $78.5(50-210)$ & & $245.5(120-492)$ & \\
Arteries & & & & \\
$\quad$ Single & $72(40-210)$ & $<0.001$ & $190(113-492)$ & $<0.001$ \\
$\quad$ MRA & $79(50-210)$ & & $240(121-492)$ & \\
\hline
\end{tabular}

Values denote median (min-max). MRA, multiple renal arteries; WIT, warm ischemia time; OT, operation time; BMI, body mass index.

Cadaveric organ donation is very rare, 7 per million, especially in our country [11]. Therefore, donor's health and safety are gaining importance in LLDN operations. Surgeons must avoid complications that affect the health of donators.

Obesity is the greatest problem in this era all around the world. In some countries, living kidney transplantation guidelines recommend that obese donors $(\mathrm{BMI}>30$ $\mathrm{kg} / \mathrm{m}^{2}$ ) must be evaluated carefully before the operations $[12,13]$. Because of lack of experience, we selected young female donors for LLDN, initially. Previously, our choice was ODN for obese donors. Before performing laparoscopic techniques on the first obese donor, we had already completed 2,552 ODN. We reflected the experience gained in open surgery on LLDN and realized that it eases the procedure of kidney donation. Our donor's mean BMI was higher than many studies in the literature [1418]. The rate was $29.3 \%$, and nearly 1 of 3 donors was obese. OT were longer in the obese group $(p=0.013)$. For
Table 4. Effects of BMI on HT and complications

\begin{tabular}{lll}
\hline & \multicolumn{2}{l}{ BMI } \\
\cline { 2 - 3 } & $<30 \mathrm{~kg} / \mathrm{m}^{2}$ & $>30 \mathrm{~kg} / \mathrm{m}^{2}$ \\
\hline Complications & & \\
Vascular injury & 2 & 6 \\
Wound infection & 2 & 6 \\
Chylous ascites & 0 & 4 \\
Fever & 3 & 1 \\
Trocar hernia & 1 & 1 \\
Pneumothorax & 0 & $3(2-9)^{*}$ \\
HT, days & $3(2-7)^{*}$ & \\
\hline
\end{tabular}

HT, hospitalization times; BMI, body mass index. * Median $(\min -\max )(p=0.013)$.

WIT, there was no significant difference between obese and nonobese donors. Despite some authors pointed out that obesity did not extend the OT and WIT significantly, 2 studies' results published by Marcelino et al. [22] and Schussler et al. supported ours [19-23]. As time progressed, with the improvement of our surgeons' skills, OT in obese donors has become similar to that in nonobese donors.

In our study, complication rates such as wound infection, trocar hernia, chylous ascites, and vascular injuries were higher in obese donors. Six of 8 donors, whose operation was completed by open donor nephrectomy because of vascular injury, were obese. Chylous ascites is very rare in LLDN. There is no need of treatment for asymptomatic patients. However, percutaneous/internal drainage, laparoscopic, or open surgery may be the options for lymphocele depending on its severity [24, 25]. We have only 4 patients who experienced chylous ascites postoperatively. One patient was reoperated with severe 

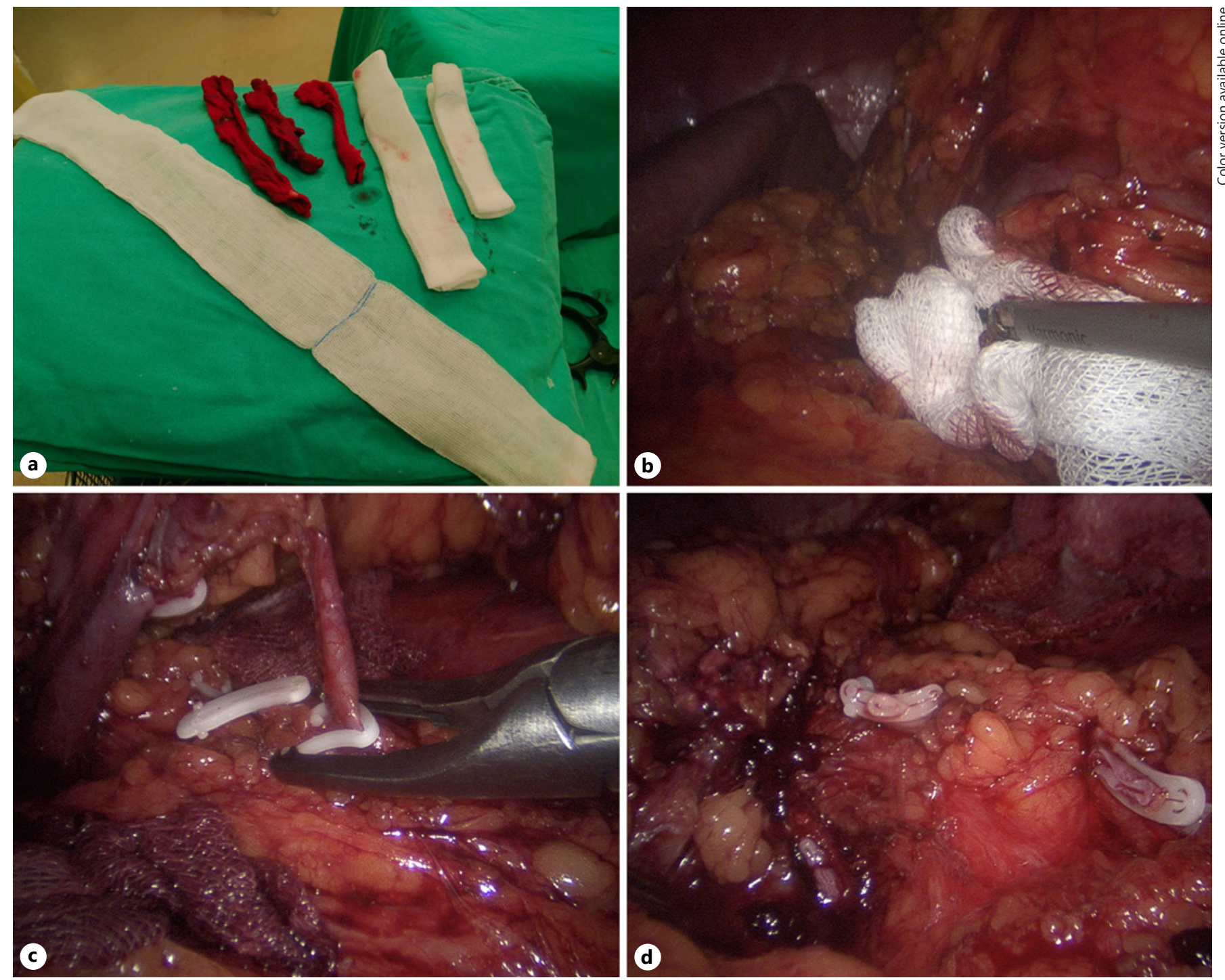

Fig. 3. Laparoscopic tips: laparoscopic and normal sponges (a), usage of laparoscopic sponges (b), and usage of Hem-O-lok clips (c, d).

abdominal pain symptoms, fever, and decreased appetite. In addition to these, hospitalization times were longer in obese donors.

Some authors pointed out that surgeons could be able to complete their learning curve of LLDN with nearly 100 operations [26]. We believe that in our center, surgeons have performed an adequate number of LLDN operations. Consequently, in the beginning, our OT was nearly $210 \mathrm{~min}$; as time passed, it gradually decreased to 40 min in some cases. The main cause of this score was the high volume of kidney transplantation that has performed in our center. Besides, high numbers bring experience.
Different opinions were mentioned in the literature about the complexity of the rLLDN. Based on the shorter right renal vein and the right renal artery's early branching, rLLDN is more complicated than ILLDN. In contrast, some authors reported that rLLDN could be performed safely as the ILLDN by skilled and experienced surgeons $[27,28]$. rLLDN has a steep learning curve. When surgeons get mastered the laparoscopy technique, complication rates and operation times may decrease in both ILLDN and rLLDN $[27,29]$. Our results show that rLLDN median OT was longer than the lLLDN's $(p=0.046)$. According to us, the main reason for this result is close attention that has been paid to dissection of the short right 
renal vein. Considering the recipient's operation, the surgeon must clip the right renal vein closest to the vena cava inferior, which means additional time loss.

In our study, WIT is defined as the time that passes between the clamping of renal artery in LLDN to the kidney's cold perfusion on the back table. WIT is related to the graft functions tightly. The more extended period of WIT reduced the graft functions, and lengthened hospitalization times also cause interstitial fibrosis/tubular atrophy on the graft. They may increase the risk of chronic allograft nephropathy, which ends with graft loss [30,31]. When comparing median WIT by sides of LLDN, left sided was shorter. Quite different results were found in the literature $[32,33]$. As explained, we thought the difference sourced from the dissection of the right renal vein and artery.

Multiple renal arteries (MRA) in LLDN are a real challenge for surgeons. Vascular injuries or longer operation times could be seen on both donors and receivers; as a result of this, graft function might deteriorate. Al-Oraifi et al. [34] noticed that operation times are longer in MRA. WIT was also found longer in another study [35]. Our results were parallel to the previous studies.

We have always extracted the kidney grafts with their Gerota's fascia. In our practice, we realized that Gerota's fascia is connected to the kidney's capsule tightly, especially in male donors older than 50 years with a muscular body. Unnecessary dissection of Gerota's fascia during LLDN may cause subcapsular kidney injuries. Besides, surgeons must be cautious of ureteral dissection because ureteral injuries are mostly seen in LLDN [36]. We preferred the Pfannenstiel incision for extracting the kidney. The incision started 3-4 cm medial from SIAS and ended $2-3 \mathrm{~cm}$ to the linea alba. The rectosigmoid junction is located close to the skin below this line, so surgeons should be careful about not damaging the intestines. While extracting the kidney, surgeons should be fast but not be panicked. At the time of starting LLDN, we routinely placed a soft drain on the surgery site. After gaining enough experience, we have only used soft drains in selected patients with bleeding risk.

Another point that needs to be emphasized is "the usage of laparoscopic sponges." In the first cases, we aggressively cauterized even minor bleedings, which causes an excessive amount of smoke. As known, smoke leads to blurring of the vision during laparoscopic surgery. Nurses tried to outflow the smoke from the intra-abdominal space, visual optics need to be cleaned, and all these steps were repeated, which means a waste of time. After that, we began to use small-sized sponges that were suitable to pass through the trocars (shown in Fig. 3a). Pressing sponges in minor bleedings was more useful than cauterization (shown in Fig. 3b). This trick point allows surgeons to continue kidney dissection instead of dealing with minor bleedings.

Another noteworthy point of LLDN, during hiler dissection, is controlling renal veins and arteries. Adipose and connective tissues around the wall of arteries and veins must be dissected carefully before clipping [37]. The veins with diameter $>4 \mathrm{~mm}$, which drain into the renal vein, should be clipped with XL clips and then sealed and cut using energy sources. Two standard surgical devices are generally used for clamping: Hem-olok clips and staplers. They have both advantages and disadvantages. Using clips provides more length for vascular anastomosis, but they might slip. Slipping of the clips causes hemorrhage perioperatively and may cost donors' life. In some cases, slippage may be delayed for hours or days. After using Hem-o-lok clips at 1,860 LLDN, we switched to vascular staplers for the rest of 617 LLDN upon the FDA's advice and the Ministry of Health. No complications have been seen related to the clips that were used before. The tricks of using Hem-olok clips safely are adequate tissue dissection, seeing the closed configuration of the latching mechanism end side of the vessel wall, and feeling the "click" when compressing the applicators (shown in Fig. 3c, d). We used 3 clips for both the renal artery and vein. Staplers transfix the vessel walls and are safer when considering the hemorrhage. However, their diameters are wider than clips; therefore, surgeons have to face the length loss of vessels. Misfiring and costs are other handicaps [38, 39].

\section{Limitations}

The most important limitation of this study is its retrospective design. Some cases were excluded from the study for missing data. Considering the duration of the study, we may have overlooked some perioperative and postoperative complications.

\section{Conclusion}

Cadaveric donation is still not usual in Turkey. Over 5,000 kidney transplantations have been performed in our center since 2009. Nearly half of the donor operation was completed by open surgery. LLDN seems to be a reliable solution for enlarging the donation pool with fewer complications and higher satisfaction rates. We shared 
our results, tips, and trick points based on the experience obtained from 2,477 LLDN cases to light the way for beginners.

\section{Statement of Ethics}

The study received approval of the local ethics committees (No. 2020/7).

\section{Conflict of Interest Statement}

The authors declare that there are no conflicts of interest.

\section{Funding Sources}

The authors did not receive any funding.

\section{Author Contributions}

Sefa Alperen Ozturk: project development, data collection, and manuscript writing. Yucel Yuksel, Halil Erbis, and Ibrahim Aaliosmanoglu: project development and data collection. Mehmet Sarier: data collection and manuscript writing. Ozlem Yayar and Asuman Yavuz: data collection. Alper Demirbas: project development and data analysis.

\section{References}

1 Sarier M, Demir M, Goktas S, Duman I, Buyukkinaci M, Yuksel Y, et al. Results of real-time multiplex polymerase chain reaction assay in renal transplant recipients with sterile pyuria. Transplant Proc. 2017 Aug;49(6): 1307-11.

2 Ratner LE, Ciseck LJ, Moore RG, Cigarroa FG, Kaufman HS, Kavoussi LR. Laparoscopic live donor nephrectomy. Transplantation. 1995 Nov 15;60(9):1047-9.

3 Shafizadeh S, McEvoy JR, Murray C, Baillie GM, Ashcraft E, Sill T, et al. Laparoscopic donor nephrectomy: impact on an established renal transplant program. Am Surg. 2000 Dec;66(12):1132-5.

4 Power RE, Preston JM, Griffin A, Martin I, Wall DR, Nicol DL. Laparoscopic vs open living donor nephrectomy: a contemporary series from one centre. BJU Int. 2006 Jul;98(1): 133-6.

5 Afaneh C, Aull MJ, Gimenez E, Wang G, Charlton M, Leeser DB, et al. Comparison of laparoendoscopic single-site donor nephrectomy and conventional laparoscopic donor nephrectomy: donor and recipient outcomes. Urology. 2011 Dec;78(6):1332-7.

6 Nanidis TG, Antcliffe D, Kokkinos C, Borysiewicz CA, Darzi AW, Tekkis PP, et al. Laparoscopic versus open live donor nephrectomy in renal transplantation: a metaanalysis. Ann Surg. 2008 Jan;247(1):58-70.

7 Fuller TF, Deger S, Büchler A, Roigas J, Schönberger B, Schnorr D, et al. Ureteral complications in the renal transplant recipient after laparoscopic living donor nephrectomy. Eur Urol. 2006 Sep;50(3):535-1.

$8 \mathrm{Ng} \mathrm{ZQ}, \mathrm{He}$ B. A proposed classification system and therapeutic strategy for chyle leak after laparoscopic living-donor nephrectomy: a single-center experience and review of the literature. Exp Clin Transplant. 2018 Apr;16(2): 143-9.

9 Hasson HM. A modified instrument and method for laparoscopy. Am J Obstet Gynecol. 1971 Jul 15;110(6):886-7.
10 Sarier M, Callioglu M, Yuksel Y, Duman E, Emek M, Usta SS. Evaluation of the renal arteries of 2,144 living kidney donors using computed tomography angiography and comparison with intraoperative findings. Urol Int. 2020;104(7-8):637.

11 Yuksel Y. Comparison of experienced centers with inexperienced centers in cadaveric organ preparation for transplantation. Ann Med Res. 2019:1

12 Guidelines for Living Donor Kidney Transplantation. Br Transplant Soc [Internet]. 2018 Mar [cited 2020 May 18]. Available from: https://bts.org.uk/wp-content/uploads/ 2018/07/FINAL_LDKT-guidelines_June2018.pdf.

13 Sawinski D, Locke JE. Evaluation of kidney donors: core curriculum 2018. Am J Kidney Dis. 2018 May 1;71(5):737-47.

14 Boentoro S, Wahyudi I, Mochtar CA, Hamid ARA. Blood transfusions in laparoscopic living donor nephrectomy: single center experience from 500 cases. Res Rep Urol. 2020;12:1.

15 Mohsin R, Shehzad A, Bajracharya U, Ali B, Aziz T, Mubarak M, et al. Laparoscopic donor nephrectomy: early experience at a single center in Pakistan. Exp Clin Transplant. 2018 Apr;16(2):138-42.

16 Cho SJ, Moon HW, Kang SM, Choi SW, Kim KS, Choi YS, et al. Evolution of laparoscopic donor nephrectomy techniques and outcomes: a single-center experience with more than 1,000 cases. Ann Transplant. $2020 \mathrm{Feb}$ 11;25:e918189.

17 Wiborg $\mathrm{MH}$, Toft A, Jahn H, Hansen LU, Lund L. Initial experience with hand-assisted laparoscopic donor nephrectomy: a singlecentre experience over 5 years. Scand J Urol. 2017 Feb;51(1):73-7.

18 Abdellaoui I, Azzabi A, Sahtout W, Sabri F, Hmida W, Achour A. Short- and long-term follow-up of living kidney donors. Saudi J Kidney Dis Transpl. 2019 Apr;30(2):401-20.
19 Unger LW, Feka J, Sabler P, Rasoul-Rockenschaub S, Györi G, Hofmann M, et al. High $\mathrm{BMI}$ and male sex as risk factor for increased short-term renal impairment in living kidney donors - Retrospective analysis of 289 consecutive cases. Int J Surg. 2017 Oct;46:172-7.

20 Raber B, Westmoreland M, Arnold D, Derek B, Lueking R, Lassiter G, et al. Laparoscopic donor nephrectomy: a single institution minimally invasive general surgeon experience 1999-2013. Am J Surg. 2017 Dec 1;214(6): $1220-5$.

21 Takagi K, Kimenai HJAN, IJzermans JNM, Minnee RC. Obese living kidney donors: a comparison of hand-assisted retroperitoneoscopic versus laparoscopic living donor nephrectomy. Surg Endosc. 2020 Nov;34(11): 4901-8.

22 Marcelino A, Mochtar CA, Wahyudi I, Hamid AR. Obese Kidney Donors in the Laparoscopic Living Nephrectomy Era: How Safe? Ann Transplant. 2016 May 10;21:297-300.

23 Schussler L, Khetan P, Peacock M, Dickstein E, LaPointe-Rudow D, Palese M, et al. Is obesity a contraindication for kidney donation? Surg Endosc. 2020;34(10):4632-7.

24 Aalami OO, Allen DB, Organ CH. Chylous ascites: a collective review. Surgery. 2000 Nov; 128(5):761-78

25 Seth A, Sharma A, Kenwar DB, Singh S. Chylous ascites: complication of laparoscopic donor nephrectomy. Case report and review of literature. Transplantation. 2019;103(4):e748.

26 Qiu Y, Song TR, Rao ZS, Wang XD, Huang $\mathrm{ZL}$, Lin T. [Learning curve of retroperitoneal laparoscopic donor nephrectomy and risk analysis of intraoperative complications]. Sichuan Da Xue Xue Bao Yi Xue Ban. 2016 Jul; 47(4):547-50.

27 Kumar A, Chaturvedi S, Gulia A, Maheshwari R, Dassi V, Desai P. Laparoscopic live donor nephrectomy: comparison of outcomes right versus left. Transplant Proc. 2018 Oct 1;50(8): 2327-32. 
28 Pandarinath SR, Choudhary B, Chouhan HS, Rudramani S, Dubey D. Transperitoneal laparoscopic left versus right live donor nephrectomy: comparison of outcomes. Indian J Urol. 2014;30(3):256-60.

29 Qiu Y, Wang X, Song T, Rao Z, Liu J, Huang $Z$, et al. Comparison of both sides for retroperitoneal laparoscopic donor nephrectomy: experience from a single center in China. Transplant Proc. 2017 Jul 1;49(6):1244-8.

30 Hellegering J, Visser J, Kloke HJ, D’Ancona FC, Hoitsma AJ, van der Vliet JA, et al. Deleterious influence of prolonged warm ischemia in living donor kidney transplantation. Transplant Proc. 2012 Jun 1;44(5):1222-6.

31 Heylen L, Naesens M, Jochmans I, Monbaliu $\mathrm{D}$, Lerut $\mathrm{E}$, Claes $\mathrm{K}$, et al. The effect of anastomosis time on outcome in recipients of kidneys donated after brain death: a cohort study. Am J Transplant. 2015;15(11):2900-7.
32 Özdemir-van Brunschot DMD, Koning GG, van Laarhoven KCJHM, Ergün M, van Horne SBCE, Rovers MM, et al. A comparison of technique modifications in laparoscopic donor nephrectomy: a systematic review and meta-analysis. PLoS One. 2015 Mar 27;10(3): e0121131.

33 Wang K, Zhang P, Xu X, Fan M. Right versus left laparoscopic living-donor nephrectomy: a meta-analysis. Exp Clin Transplant. 2015 Jun; 13(3):214-26.

34 Al-Oraifi I, Tawfeeq M, Al-Hellow H, AlQahtani MS, Al-Bugami MM, Al-Shahrani A, et al. Laparoscopic donor nephrectomy of dual renal artery kidneys: single center experience. Chirurgia. 2017 Apr;112(2):124-9.
35 Bandín Musa AR, Montes de Oca J. Hand-assisted laparoscopic nephrectomy in livingdonor kidneys with multiple arteries: experience of a transplant center. Exp Clin Transplant. 2016 Apr;14(2):153-6.

36 Yuksel Y. Üreter Dubplikasyonlu Greft Böbreklerde Nakil Tecrübemiz. SDÜ Tip Fakültesi Derg. 2019 Jun 1;26(2):195-200.

37 Buell JF, Hanaway MJ, Woodle ES. Maximizing renal artery length in right laparoscopic donor nephrectomy by retrocaval exposure of the aortorenal junction. Transplantation. 2003 Jan;75(1):83-5.

38 Liu Y, Huang Z, Chen Y, Liao B, Luo D, Gao $\mathrm{X}$, et al. Staplers or clips? Medicine. $2018 \mathrm{Nov}$ 9;97(45):e13116.

39 McGregor TB, Patel P, Sener A, Chan G. Vascular control during laparoscopic kidney donation. Can J Surg. 2017 Jun;60(3):150-1. 